\title{
Reduced adhesion of macrophages on anodized titanium with select nanotube surface features
}

This article was published in the following Dove Press journal:

International Journal of Nanomedicine

22 August 201I

Number of times this article has been viewed

\author{
Amancherla Rajyalakshmi' \\ Batur Ercan ${ }^{2,3}$ \\ K Balasubramanian' \\ Thomas J Webster ${ }^{2,3}$
}

'Non-Ferrous Materials Technology Development Centre, Hyderabad, India; ${ }^{2} \mathrm{School}$ of Engineering,

${ }^{3}$ Department of Orthopedics, Brown

University, Providence, RI, USA
Correspondence: Thomas J Webster School of Engineering and Department of Orthopedics, Brown University, 184 Hope Street, Providence, RI 02912, USA

$\mathrm{Tel}+\mathrm{I} 4018632318$

$\mathrm{Fax}+\mathrm{I} 4018639107$

Email thomas_webster@brown.edu

\begin{abstract}
One of the important prerequisites for a successful orthopedic implant apart from being osteoconductive is the elicitation of a favorable immune response that does not lead to the rejection of the implant by the host tissue. Anodization is one of the simplest surface modification processes used to create nanotextured and nanotubular features on metal oxides which has been shown to improve bone formation. Anodization of titanium (Ti) leads to the formation of $\mathrm{TiO}_{2}$ nanotubes on the surface, and the presence of these nanotubes mimics the natural nanoscale features of bone, which in turn contributes to improved bone cell attachment, migration, and proliferation. However, inflammatory cell responses on anodized Ti remains to be tested. It is hypothesized that surface roughness and surface feature size on anodized $\mathrm{Ti}$ can be carefully manipulated to control immune cell (specifically, macrophages) responses. Here, when Ti samples were anodized at $10 \mathrm{~V}$ in the presence of $1 \%$ hydrofluoric acid (HF) for 1 minute, nanotextured (nonnanotube) surfaces were created. When anodization of Ti samples was carried out with $1 \% \mathrm{HF}$ for 10 minutes at $15 \mathrm{~V}$, nanotubes with $40-50 \mathrm{~nm}$ diameters were formed, whereas at $20 \mathrm{~V}$ with $1 \% \mathrm{HF}$ for 10 minutes, nanotubes with $60-70 \mathrm{~nm}$ diameters were formed. In this study, a reduced density of macrophages was observed after 24 hours of culture on nanotextured and nanotubular Ti samples which were anodized at 10, 15, and $20 \mathrm{~V}$, compared with conventional unmodified Ti samples. This in vitro study thus demonstrated a reduced density of macrophages on anodized $\mathrm{Ti}$, thereby providing further evidence of the greater efficacy of anodized Ti for orthopedic applications.
\end{abstract}

Keywords: anodization, titanium implants, $\mathrm{TiO}_{2}$ nanotube

\section{Introduction}

Improving the integration and tissue growth at the bone-metal interface of orthopedic devices has been a primary focus of recent biomaterial research. The development and use of novel nanophase materials in orthopedics has provided a way to promote bone cell responses. A nanophase material is one with constituent structural units (such as grain size, particle size, width, and height) less than $100 \mathrm{~nm}$ in at least one direction. ${ }^{1}$ Nanophase materials, compared with conventional phase or currently used materials, possess surface characteristics (such as topography, wettability, charge, and surface free energy) that may be more reactive for interactions with select proteins from plasma such as fibronectin and vitronectin, ${ }^{2,3}$ and subsequently cells like osteoblasts. ${ }^{4,5}$ Moreover, the adherence of bacterial cells to nanorough Ti surfaces created by electron beam evaporation was reduced when compared with conventional unmodified Ti surfaces. ${ }^{6}$ It was demonstrated that through the careful selection of nanometer surface properties, one can increase select protein adsorption and bioactivity (while maintaining favorable 
wettability, chemistry, and crystallinity) to decrease bacterial cell adhesion. ${ }^{6}$ Numerous studies have clearly documented that material properties (such as roughness and energy) of nanophase Ti, compared with conventional or nanosmooth Ti of the same chemistry, promote responses from bone resulting in increased tissue regeneration., ${ }^{4,5}$ Such behavior has been traced back to the fact that nature itself exists in the nanometer regime, especially bone, which shows a large amount of nanostructured surface roughness not emulated in today's micron-structured, but nanosmooth, implants.

In addition, for ceramics it has been observed that responses of macrophages are reduced on nanophase compared with conventional alumina $\left(\mathrm{Al}_{2} \mathrm{O}_{3}\right) .{ }^{1}$ In that study, reduced macrophage density after 24 hours was observed on alumina compacts with greater nanometer surface roughness accompanied by changes in crystallinity. Similarly, nanorod structures of $\mathrm{ZnO}$ have been demonstrated to reduce the number of adherent macrophages compared with flat $\mathrm{ZnO}$ substrates and glass. ${ }^{7}$

Observations have also shown that organized, nanostructured topographical surfaces (such as patterns, grooves, pores, ridges, orthogonal and cylindrical imprints, wells, and nodes) dictate and enhance cellular (such as for osteoblasts and vascular endothelial cells) morphology and motility to promote subsequent cell functions. ${ }^{8,9}$ For example, endothelial cells on highly parallel nanopatterned gold and silicon surfaces (60-150 nm pattern size), created using orthogonal biofunctionalization imprint lithography, formed confluent layers in the direction of the nanopatterns which resembled the natural interior of living blood vessels. ${ }^{10}$ In addition, endothelial cell filopodia extended in the direction of the nanopatterned features. Endothelial cells have also been studied on linearly, aligned, and grooved nanopatterned titanium (Ti) surfaces (750-100 $\mu \mathrm{m}$ pattern size) created using plasma-based dry etching techniques. Results demonstrated enhanced endothelial cell coverage in addition to endothelial cell alignment similar to the natural endothelium. ${ }^{11}$ Such data indicate the importance of patterns of nanofeatures, not just random nanofeatures for enhancing cell responses.

Fibroblasts have also been studied on parallel cylindrical nanocolumns (center-to-center spacing of $230 \mathrm{~nm}$ ) synthesized on poly(methyl methacrylate) by colloidal lithography. ${ }^{12}$ It was observed that such fibroblasts have a higher number of filopodia compared with fibroblasts on flat or nanosmooth $\mathrm{Ti}$.

However, when an implant is surgically introduced into the body, the biomaterial will be treated as a foreign object, recruiting macrophages first then fibroblasts to cover the implant with a soft fibrous tissue preventing successful integration of the implant with natural tissue. The chronic inflammation phase, which leads to the formation of a detrimental fibrous capsule around the implant, is characterized by the presence of monocytes and macrophages. Further, lymphocytes and plasma cells are recruited to the site of the implant and begin antibody production, formation of blood vessels, and formation of connective tissue. Macrophages continue to increase in number in order to remove the foreign object. All these events happen long before osteoblasts (or fibroblasts) arrive to initiate bone tissue formation. Macrophages begin to produce and secrete biologically active molecules, including fibroblast growth factor and transforming growth factor- $\beta$, into the surrounding area and elicit a wound-healing response. ${ }^{13}$ The development of the fibrous capsule inhibits bonding of the biomaterial to the surrounding bone, thus preventing mechanical stability of the device due to stress-strain imbalances. Therefore, for developing new improved orthopedic implant surfaces, one of the goals is to promote the attachment, proliferation, and growth of osteoblasts ${ }^{14}$ while preventing the attachment and chronic presence of macrophages; the latter was the objective of this present study as it has not been studied to date on anodized nanostructured Ti.

\section{Materials and methods Materials}

Ti foils (100 mm $\times 100 \mathrm{~mm} \times 1 \mathrm{~mm} ; 99.2 \%$ pure; Alfa Aesar, Ward Hill, MA) were cut into $10 \mathrm{~mm} \times 10 \mathrm{~mm}$ squares using a shear cutter. All substrates were cleaned with 5\% nitric acid for 20 minutes followed by sonication in acetone, 70\% ethanol, and deionized water for 10 minutes. Substrates were then dried in an oven at $40^{\circ} \mathrm{C}$ for 15 minutes. Some of these substrates served as conventional, unanodized Ti substrates used throughout the present work, while others were used in the section below for anodization. Prior to cell culture experiments, these substrates were sterilized in a steam autoclave at $120^{\circ} \mathrm{C}$ and $17 \mathrm{psi}$ for 30 minutes.

\section{Anodization}

Prior to anodization, Ti substrates were immersed in a dilute acidic mixture of nitric acid and hydrofluoric acid (HF) for 5 minutes to remove the thin oxide layer that spontaneously forms on the Ti surface in the presence of air. Titania nanotube arrays were then formed on the Ti surface by anodization. Anodization is an electrolytic passivation process used to increase the thickness of the natural oxide layer on metal surfaces, in this case Ti. This process was conducted with a direct-current powered electrochemical cell, which consisted of a two-electrode configuration: a platinum mesh 
which served as the cathode, and Ti foils which served as the anode. To fabricate nanotubular Ti surfaces, the anodization process took place in $1 \mathrm{wt} \% \mathrm{HF}$ for 10 minutes at $15 \mathrm{~V}$ and $20 \mathrm{~V}^{15}$ To fabricate nanotextured Ti surfaces, the anodization process took place in $1 \mathrm{wt} \% \mathrm{HF}$ for 1 minute at a constant voltage of $10 \mathrm{~V}$. The nanotubular and nanotextured Ti substrates were rinsed with large amounts of deionized water immediately after anodization, air dried, and sterilized under ultraviolet light for 3 hours per substrate side.

\section{Surface characterization}

For qualitative surface roughness analysis, scanning electron microscopy (SEM) was performed on the conventional, nanotubular, and nanotextured Ti substrates. Images were taken using an LEO 1530VP SEM (LEO, Oberkochen, Germany) at varying magnifications. Digital images were created using secondary electrons collected with an in-lens detector at an accelerating voltage of $3 \mathrm{kV}$ for conventional Ti substrates and $5 \mathrm{kV}$ for nanotubular and nanotextured Ti substrates.

For surface roughness measurements, an atomic force microscope (AFM) (Asylum Research, Santa Barbara, CA) was used to scan the Ti substrates. Each sample was analyzed in ambient air under noncontact mode using a silicone ultra sharp cantilever (probe tip radius of $10 \mathrm{~nm}$ ) (MikroMasch, Wilsonville, OR). AFM fields of $1 \mu \mathrm{m} \times 1 \mu \mathrm{m}$ were analyzed, and the scan rate was chosen as $1 \mathrm{~Hz}$. IgorPro image analysis software (WaveMetrics Inc, Portland, OR) was used to generate micrographs and to quantitatively compare the root-mean-square roughness (rms) of the Ti substrates.

For chemical analysis of the top surface layer of the $\mathrm{T} i$ samples, electron spectroscopy for chemical analysis was performed using a Perkin Elmer 5500 Multitechnique Surface Analyzer System (Waltham, MA). An aluminum K-alpha monochromatized X-ray source was used to stimulate the photoemission of the inner shell electrons on the surfaces. The energy of these electrons was then recorded and analyzed for all substrates. Wide scans of the Ti were used to generate low-resolution spectra to identify and quantify the percentage of different elements up to a depth of $100 \AA$.

Phase analysis was carried out by X-ray diffraction (XRD) analysis using a D500 Siemens diffractometer (Bruker AXS Inc, Madison, WI). Spectra were taken using a power supply of $30.0 \mathrm{~mA}$ and $40.0 \mathrm{kV}$.

Water contact angles were investigated using an EasyDrop drop shape analysis system (Kruss, Hamburg, Germany). The contact angle of $1 \mu \mathrm{L}$ double distilled water sessile droplets ( 5 seconds after being placed on the surface) was measured for all sample types.

\section{Macrophage cultures}

The IC-21 macrophage cell line was used (TIB-186; ATCC, Manassas, VA) for determining an immune response. Macrophages were cultured according to ATCC instructions in RPMI-1640 medium (Invitrogen, Carlsbad, CA), which contained $2 \mathrm{mM}$ L-glutamine, $1.5 \mathrm{gL}^{-1}$ sodium bicarbonate, $4.5 \mathrm{gL}^{-1}$ glucose (Sigma-Aldrich, St Louis, MO), $10 \mathrm{mM}$ HEPES (4-[2-hydroxyethyl]-1-piperazineethanesulfonic acid) (Sigma-Aldrich) and $1.0 \mathrm{mM}$ sodium pyruvate (Invitrogen), with 10\% fetal bovine serum (HyClone Laboratories Inc, Logan, UT) and 1\% penicillin/streptomycin (HyClone) under standard incubator conditions $\left(37^{\circ} \mathrm{C}\right.$, humidified, $5 \%$ $\mathrm{CO}_{2} / 95 \%$ air environment). Cells at population numbers 3-16 were used in the experiments.

\section{Macrophage density assays}

Macrophages were seeded at 3500 cells $\mathrm{cm}^{2}$ per substrate and were cultured in a humidified 5\% $\mathrm{CO}_{2} / 95 \%$ air environment at $37^{\circ} \mathrm{C}$ for 24 hours. Conventional, unanodized, Ti sheets served as a reference substrate. After 24 hours, nonadherent macrophages were removed by rinsing in phosphate-buffered saline (PBS). Macrophages adherent on the substrates were fixed with $4 \%$ formalin in PBS and stained with both rhodamine phalloidin ${ }^{16}$ (R415) (Molecular Probes, Eugene, OR) and DAPI (4',6-diamidino-2-phenylindole) (33258) (Sigma-Aldrich) according to the manufacturer's instructions. F-actin filaments and cell nuclei ${ }^{17,18}$ were visualized using tetramethyl rhodamine iso-thiocyanate and DAPI, respectively. Cell images were taken using a Leica DM 5500B microscope system with image analysis software. Cell density was determined by counting cells in five random fields per substrate.

\section{Statistical analysis}

The cell experiments were run in triplicate and repeated six times per substrate type. The statistical significance for the cell density assays was considered at $P<0.001$. Statistical analysis was carried out using Microsoft Excel (Microsoft, Redmond, WA).

\section{Results and discussion Surface characterization}

The unmodified Ti, as purchased from the vendor, possessed nearly smooth surface features at the nanometer level as visualized under SEM (Figure 1A). In contrast, after subjecting to anodization, the Ti substrates possessed a high degree of nanometer surface features, thus creating a more nanometer rough surface topography. 

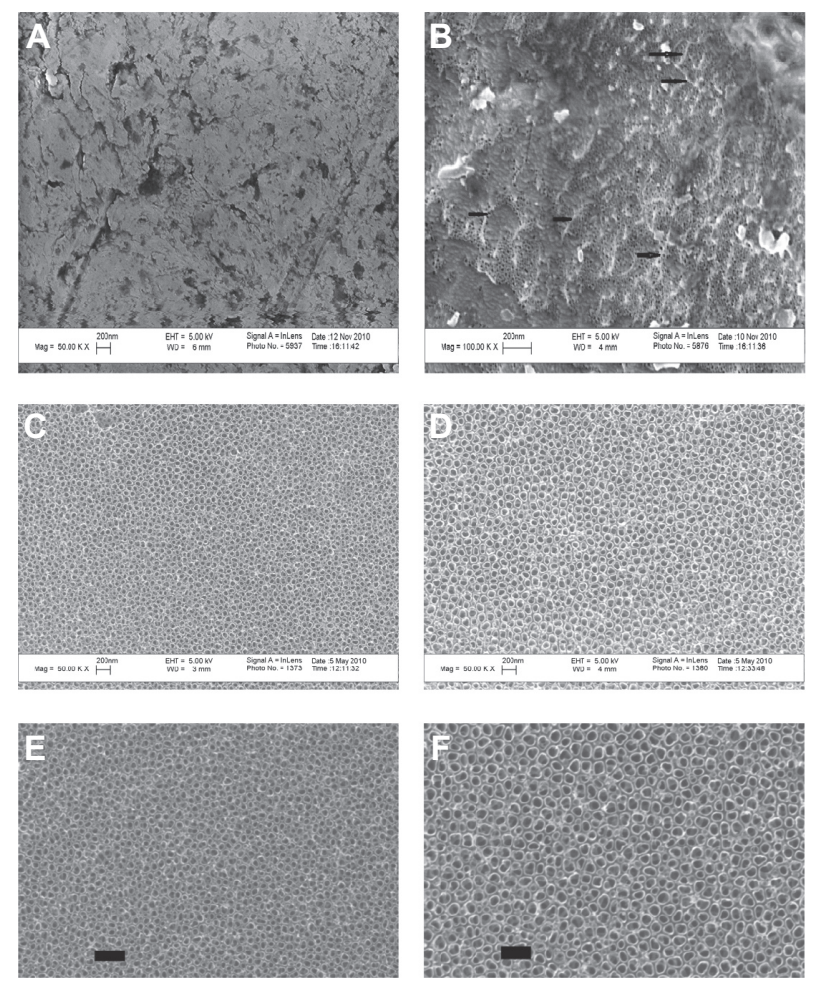

Figure I Scanning electron microscopy images. (A) Unanodized Ti sample showing a nearly smooth surface at the nanometer level. (B) Ti sample anodized in I\% HF for I minute at $10 \mathrm{~V}$ showing a nanotextured non-nanotubular surface; the black arrows show the ridge-like nanotextures interspersed between the tiny holes. (C) Ti sample anodized with $1 \% \mathrm{HF}$ for 10 minutes at $15 \mathrm{~V}$ showing nanotubes of $40-50 \mathrm{~nm}$ diameters. (D) Ti sample anodized with $1 \% \mathrm{HF}$ for 10 minutes at $20 \mathrm{~V}$ showing nanotubes of 60-70 nm diameters. (E) Enlarged portion of nanotubes of 40-50 nm diameter. (F) Enlarged portion shows nanotubes 60-70 nm diameter (scale bar $=200 \mathrm{~nm}$ ). Abbreviations: $\mathrm{HF}$, hydrofluoric acid; $\mathrm{Ti}$, titanium.

Anodization, which was carried out for 1 minute in $1 \%$ $\mathrm{HF}$ at $10 \mathrm{~V}$ resulted in a Ti substrate containing nanotextured surface features (Figure 1B). Increasing the anodization time (10 minutes) with the same concentration of $\mathrm{HF}$ at $15 \mathrm{~V}$ and $20 \mathrm{~V}$ resulted in a Ti surface that contained nanotubular-like structures with an inner diameter of $40-50 \mathrm{~nm}$ and $60-70 \mathrm{~nm}$, respectively, as estimated from the SEM images (Figure 1C and D).

AFM results confirmed greater nanoscale roughness for the anodized nanotubular Ti samples, with $60-70 \mathrm{~nm}$ diameter tubes, $40-50 \mathrm{~nm}$ diameter tubes, and nanotextured Ti compared with unanodized Ti (Table 1).

Surface chemistry characterization ${ }^{19}$ revealed different chemistry among the various Ti samples fabricated in this study (Table 2). Most significantly, the unanodized Ti did not have any fluorine present on the surface, whereas all other samples did since the anodization electrolyte solution contained fluorine.

Due to the above changes in surface roughness and chemistry, water contact angles varied on the Ti samples of
Table I Quantitative data obtained from atomic force microscopy analysis indicated that substrates created by anodization contained more nanofeatures than unanodized $\mathrm{Ti}$

\begin{tabular}{lc}
\hline Sample & $\begin{array}{l}\text { Root-mean-square } \\
\text { roughness }(\mathbf{n m})\end{array}$ \\
\hline Unanodized $\mathrm{Ti}$ & $6.54 \pm 0.37^{\mathrm{a}}$ \\
Nanotextured (non-nanotubular) $\mathrm{Ti}$ & $7.97 \pm 0.83$ \\
Nanotubular $\mathrm{Ti}(40-50 \mathrm{~nm}$ tubes) & $8.31 \pm 0.47$ \\
Nanotubular $\mathrm{Ti}(60-70 \mathrm{~nm}$ tubes) & $10.37 \pm 1.33$ \\
\hline
\end{tabular}

Notes: No significant difference was observed for the micron surface topography scans. Values are mean \pm standard error of the mean, $n=3$. ${ }^{a} p<0.01$ compared with all other samples.

Abbreviation: $\mathrm{Ti}$, titanium.

interest to the present study. Specifically, the unanodized Ti had a contact angle of $61^{\circ}$, while the nanotextured, anodized Ti with $60-70 \mathrm{~nm}$ nanotubular diameters and anodized Ti with 40-50 nm nanotubular diameters had contact angles of 10, 7, and 7, respectively. Lastly, XRD revealed similar crystallinity among the Ti samples, with similar amounts of anatase and rutile phases (data not shown).

\section{Macrophages well spread on conventional unanodized $\mathrm{Ti}$}

Macrophages adherent to the substrates after 24 hours of culture followed an interesting adhesion pattern as shown by the SEM pictures (Figure 2). Under fluorescence microscopy, when cultured for 24 hours, most of the macrophages on conventional $\mathrm{Ti}$ after 24 hours clearly showed large nuclei ${ }^{20}$ stained blue with DAPI and pseudopodia stained green with rhodamine phalloidin where actin filaments were usually found. The macrophages cultured on conventional Ti were larger and more extensively spread compared with the other substrates after 24 hours of culture. In contrast, most of the macrophages cultured on the nanotextured and nanotubular Ti showed round morphologies with little spreading.

Table 2 Atomic percentages of elements in the outermost layers of $\mathrm{Ti}$, as determined by electron spectroscopy for chemical analysis

\begin{tabular}{llllll}
\hline Material & \multicolumn{6}{l}{ Elemental concentration (\%) } \\
\cline { 2 - 6 } & Ti2p & OIs & CIs & FIs & Ti/O \\
\hline Unanodized $\mathrm{Ti}$ & 19.93 & 51.29 & 28.79 & 0 & 0.39 \\
$\begin{array}{l}\text { Nanotextured } \\
\text { (non-nanotubular) } \mathrm{Ti}\end{array}$ & 22.70 & 40.21 & 23.50 & 13.59 & 0.56 \\
$\begin{array}{l}\text { Anodized Ti } \\
\text { (40-50 nm tubes) }\end{array}$ & 21.38 & 43.22 & 27.28 & 8.12 & 0.49 \\
$\begin{array}{l}\text { Anodized Ti } \\
(60-70 \mathrm{~nm} \text { tubes) }\end{array}$ & 11.28 & 21.35 & $62.6 \mathrm{I}$ & 4.76 & 0.53 \\
\hline
\end{tabular}

Abbreviation: $\mathrm{Ti}$, titanium. 

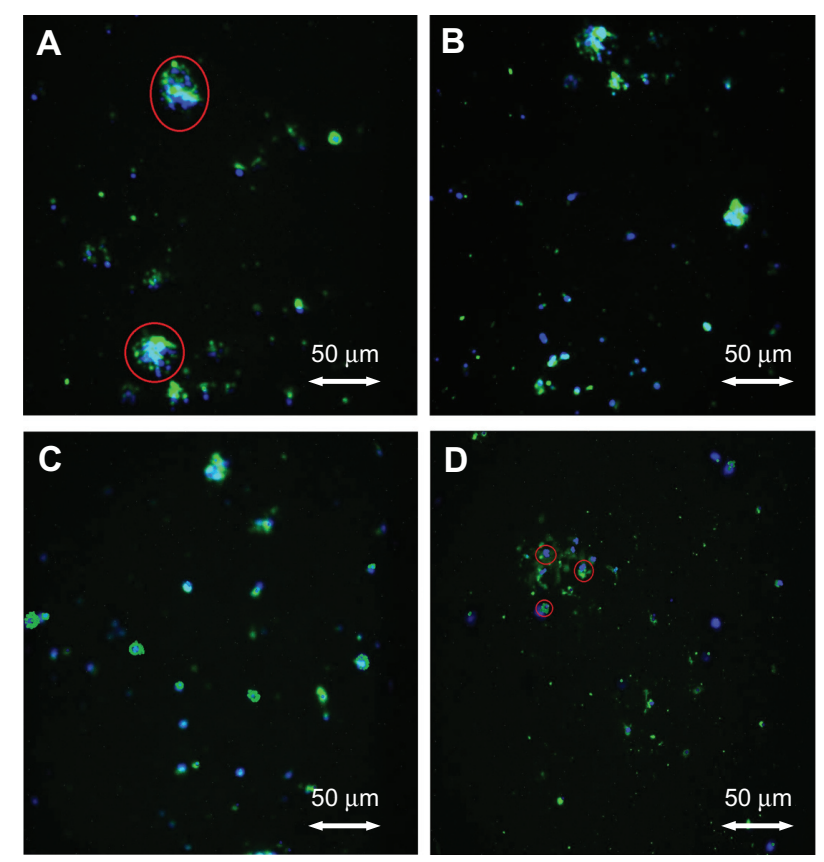

Figure 2 Fluorescent microscopy images. (A) Adherent macrophages on unanodized $\mathrm{Ti}$; round blue-green shape encircled by a red line shows a well spread macrophage. (B) Nanotextured, non-nanotubular Ti. (C) Nanotubular Ti with 40-50 nm diameters, after 24 hours of culture. (D) Nanotubular Ti with 60-70 nm diameters, after 24 hours of culture, showing macrophages (encircled in red lines) with little spreading. Abbreviation: $\mathrm{Ti}$, titanium.

\section{Reduced macrophage density on nanotextured and nanotubular $\mathrm{Ti}$}

As expected from the previous section, results of the present study demonstrated higher macrophage densities on conventional unanodized $\mathrm{Ti}$ than on nanotextured and nanotubular Ti after 24 hours of culture. Nanotubular Ti samples fabricated by anodization (Figure 3C and D) reduced macrophage density after 24 hours of culture when compared with that on conventional unanodized Ti. The maximum adherence of macrophages was observed on conventional Ti. Macrophage density on nanotextured Ti reduced $67 \%$ compared with conventional unanodized Ti. The nanotubular Ti samples anodized at $15 \mathrm{~V}$ showed a slightly lowered macrophage density (45\%), whereas the samples anodized at $20 \mathrm{~V}$ showed the lowest macrophage density (30\%) compared with unmodified Ti.

The size of a murine macrophage is about $13 \mu \mathrm{m}$ in diameter. ${ }^{21}$ Macrophage-associated phenomena such as phagocytosis and macrophage-mediated clearance should be, at least in part, dependent on macrophage adhesion to a solid substrate surface. This study provided the first ever evidence of less macrophage numbers on $\mathrm{Ti}$ anodized to

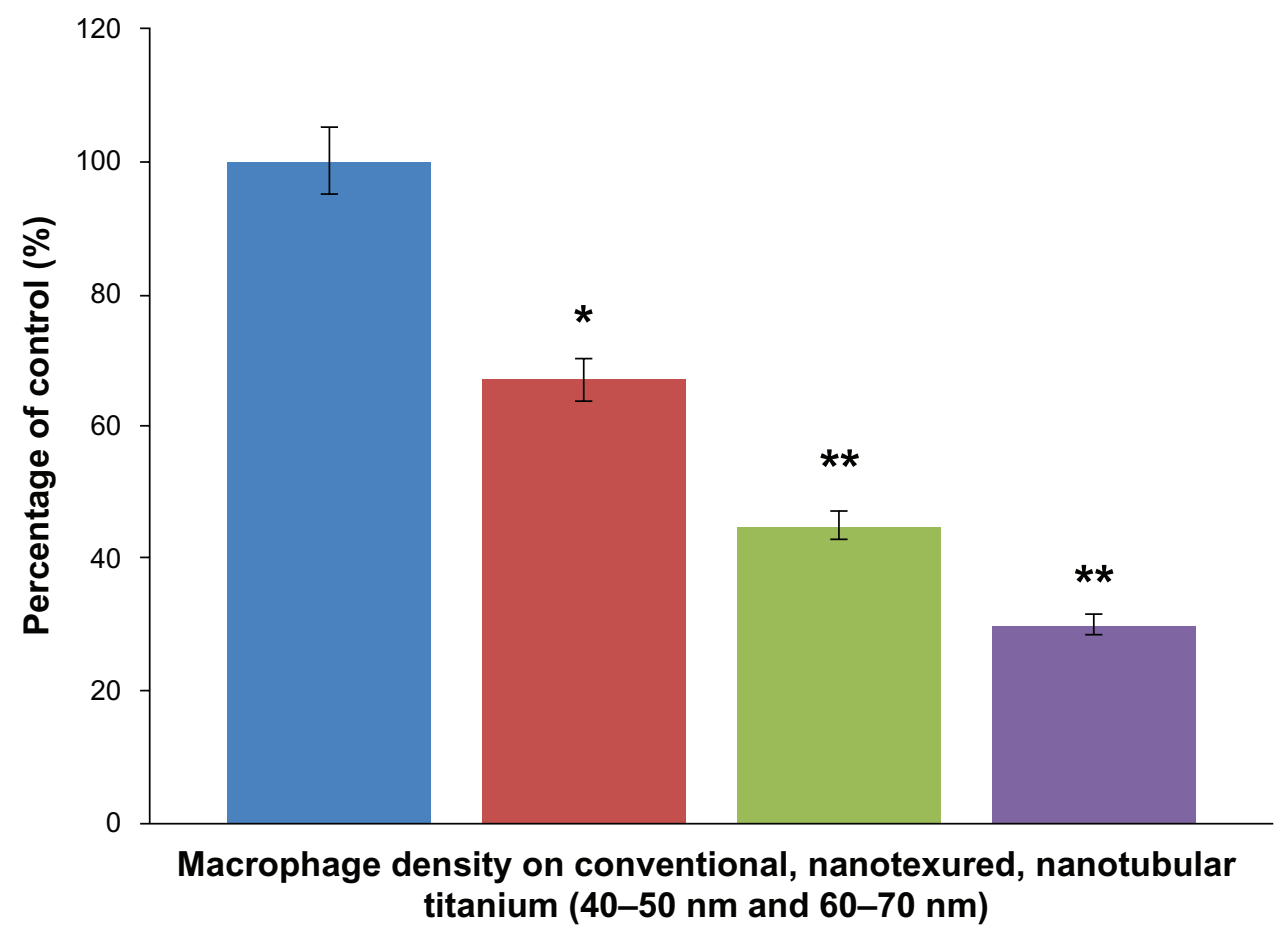

a. Conventional unmodified titanium

c. Nanotubular titanium $(40-50 \mathrm{~nm})$

b. Nanotextured (non-nanotube titanium)

d. Nanotubular titanium $(60-70 \mathrm{~nm})$

Figure 3 Macrophage density on conventional and anodized $\mathrm{Ti}$ samples. Macrophage density on conventional unmodified $\mathrm{Ti}$, nanotextured non-nanotubular $\mathrm{Ti}$ and nanotubular $\mathrm{Ti}$ (tubes with diameters of $40-50 \mathrm{~nm}$ and $60-70 \mathrm{~nm}$, respectively), $\mathrm{n}=6$, data are mean \pm standard error of the mean.

Notes: ${ }^{*} * \mathrm{P}<0.000 \mathrm{I},{ }^{*} \mathrm{P}<0.0002$ compared with conventional unanodized Ti.

Abbreviation: $\mathrm{Ti}$, titanium. 
possess nanotubes $60-70 \mathrm{~nm}$ in diameter compared with unanodized $\mathrm{Ti}$.

Collectively, the results of this in vitro study suggest that substrates presenting patterned nanotubular surface features may dramatically reduce the number of adherent macrophages compared with the unmodified nanosmooth substrates, which could indicate a role for Ti nanotopographies to reduce macrophage attachment. Several of the material characterization studies performed here may provide the answer as to why macrophage function was altered on $\mathrm{Ti}$ with nanotubular surface features. Surface roughness, chemistry, and wettability (or energy) was altered on nanotubular Ti compared with unanodized Ti. Future studies will need to isolate these parameters to determine which one(s) are responsible for reducing macrophage functions.

Another significant observation of this study is the lower adhesion of macrophages after 24 hours of culture on nanotubular Ti samples with nanotubes $60-70 \mathrm{~nm}$ in diameter compared with the nanotubular samples with nanotubes $40-50 \mathrm{~nm}$ in diameter. While these two nanotubular Ti substrates had similar wettability, their chemistry and roughness were slightly different, which may explain this observation. In this study, macrophages were allowed to grow in normal RPMI-1640 medium without any specialized activation or inhibition factors. It seems that the nanotopography of the anodized Ti scaffolds influenced the adhesion of the macrophages, which should be further investigated with respect to their longer-term functions to obtain further insights into the overall responses of macrophages. In addition, since previous studies have correlated altered nanostructured features with altered initial protein interactions, future studies should evaluate initial protein interactions that may explain the ability of anodized nanostructured Ti to reduce macrophage density without the use of anti-inflammatory drugs.

\section{Conclusion}

The results of the present study clearly demonstrated decreased numbers of macrophages adhered to nanotubular Ti surfaces fabricated by anodization. Also, when the morphological features were considered, macrophages cultured on anodized $\mathrm{Ti}$ appeared to be less well spread compared with unanodized conventional nanosmooth Ti (controls). Most importantly, when considering other studies noting increased osteoblast adhesion, proliferation, and long-term functions (such as alkaline phosphatase secretion and calcium deposition) on anodized Ti, the current study demonstrated that nanoscale topographies on Ti should be strongly considered to improve orthopedic implant efficacy.

\section{Acknowledgments}

The research work reported in this manuscript was carried out under the framework of Indo-US Joint Public-Private Networked Center on Biomaterials for Healthcare (Grant No. IUSSTF/JC/Biomaterials/15-2008/2008-09), funded by the Indo-US Science and Technology Forum. The authors acknowledge the travel support to visit Brown University provided by the forum. The help of Mr Anthony McCormick with SEM at Brown University is gratefully acknowledged.

\section{Disclosure}

The authors report no conflicts of interest in this work.

\section{References}

1. Khang D, Liu-Snyder P, Pareta R, Lu J, Webster TJ. Reduced responses of macrophages on nanometer surface features of altered alumina crystalline phases. Acta Biomaterialia. 2009;5:1425-1432.

2. Dalton BA, McFarland CD, Underwood PA, Steele JG. Role of heparin binding domain of fibronectin in attachment and spreading of human bone-derived cells. J Cell Sci. 1995;108:2083-2092.

3. Wilson CJ, Clegg RE, Leavesley DI, Pearcy MJ. Mediation of biomaterial-cell interactions by adsorbed proteins: a review. Tissue Eng. 2005;11:1-18.

4. Webster TJ, Siegel RW, Bizios R. Osteoblast adhesion on nanophase ceramics. Biomaterials. 1999;20:1221-1227.

5. Webster TJ, Ergun C, Doremus RH, Siegel RW, Bizios R. Enhanced functions of osteoblasts on nanophase ceramics. Biomaterials. 2000; 21:1803-1810.

6. Puckett SD, Taylor E, Raimondo T, Webster TJ. The relationship between the nanostructure of titanium surfaces and bacterial attachment. Biomaterials. 2010;31:706-713.

7. Zaveri TD, Dolgova NV, Chu BH, et al. Contributions of surface topography and cytotoxicity to the macrophage response to zinc oxide nanorods. Biomaterials. 2010;31:2999-3007.

8. Yim EK, Leong KW. Significance of synthetic nanostructures in dictating cellular response. Nanomedicine. 2005;1:10-21.

9. Flemming RG, Murphy CJ, Abrams GA, Goodman SL, Nealey PF. Effects of synthetic micro- and nano-structured surfaces on cell behavior. Biomaterials. 1999;20:573-588.

10. Gaubert HE, Frey W. Highly parallel fabrication of nanopatterned surfaces with nano-scale orthogonal bio functionalization imprint lithography. Nanotechnology. 2007;18:135101.

11. Lu J, Rao MP, MacDonald NC, Khang D, Webster TJ. Improved endothelial cell adhesion and proliferation on patterned titanium surfaces with rationally designed, micrometer to nanometer features. Acta Biomaterialia. 2008;4:192-201.

12. Dalby MJ, Riehle MO, Sutherland DS, Agheli H, Curtis AS. Changes in fibroblast morphology in response to nano-columns produced by colloidal lithography. Biomaterials. 2004;25:5415-5422.

13. Park JE, Barbul A. Understanding the role of immune regulation in wound healing. Am J Surg. 2004;187:11S-16S.

14. Webster TJ, Ergun C, Doremus RH, Siegel RW, Bizios R. Specific proteins mediate enhanced osteoblast adhesion on nanophase ceramics. J Biomed Mater Res. 2000;51:475-483.

15. Yao C, Slamovich EB, Webster TJ. Enhanced osteoblast functions on anodized titanium with nanotube-like structures. J Biomed Mater Res A. 2008;85:157-166.

16. Folkman J, Moscona A. Role of cell shape in growth control. Nature. 1978;273:345-349.

17. Delon I, Brown NH. Integrins and the actin cytoskeleton. Curr Opin Cell Biol. 2007;19:43-50. 
18. Anselme K. Osteoblast adhesion on biomaterials. Biomaterials. 2000; 21:667-681.

19. Jayaraman M, Meyer U, Buhner M, Joos U, Wiesmann HP. Influence of the titanium surfaces on attachment of osteoblast-like cells in vitro. Biomaterials. 2004;25:625-631.
20. Bloebaum RD, Dupont JA. Osteolysis from a press-fit hydroxyapatitecoated implant. A case study. J Arthroplasty. 1993;8:195-202.

21. Krombach F, Münzing S, Allmeling AM, Gerlach JT, Behr J, Dörger M. Cell size of alveolar macrophages: an interspecies comparison. Environ Health Perspect. 1997;105(Suppl 5):1261-1263.

\section{Publish your work in this journal}

The International Journal of Nanomedicine is an international, peerreviewed journal focusing on the application of nanotechnology in diagnostics, therapeutics, and drug delivery systems throughout the biomedical field. This journal is indexed on PubMed Central, MedLine, CAS, SciSearch $®$, Current Contents ${ } /$ Clinical Medicine,
Journal Citation Reports/Science Edition, EMBase, Scopus and the Elsevier Bibliographic databases. The manuscript management system is completely online and includes a very quick and fair peer-review system, which is all easy to use. Visit http://www.dovepress.com/ testimonials.php to read real quotes from published authors.

Submit your manuscript here: http://www.dovepress.com/international-journal-of-nanomedicine-journal 